\title{
La composición escrita: aportaciones teóricas y recomendaciones legales para su enseñanza en educación primaria
}

\author{
María José Rabazo Méndez \\ Juan Manuel Moreno Manso
}

Departamento de Psicología y Sociología de la Educación Universidad de Extremadura Badajoz

\section{España}

mjrabazo@unex.es 


\section{Resumen}

Uno de los principales objetivos para la enseñanza obligatoria está relacionado con la enseñanza de la composición escrita, no sólo por su importancia en la formación personal e intelectual del alumno, sino por su implicación en el desarrollo tecnológico y cultural de una sociedad.

El objetivo de este artículo es estudiar cómo quedan reflejadas las aportaciones arrojadas desde los diferentes modelos teóricos sobre composición escrita en la legislación educativa vigente así como el tratamiento que esta actividad recibe en la enseñanza primaria (6 a 12 años). Para ello, se han revisado las aportaciones de Vygotsky sobre el concepto y las características del lenguaje monológico escrito, los modelos de Hayes y Flower (1980), las contribuciones de Bereiter y Scardamalia (1987) y la revisión de Hayes (1996) sobre el modelo de 1980, se han estudiado los Reales Decretos que establecen las enseñanzas mínimas y el currículum en educación primaria para el área de lengua castellana y literatura (Real Decreto 1006/1991 y Real decreto 1344/1991) y se han analizado las actividades propuestas en los libros de textos para la enseñanza/aprendizaje de la composición escrita.

Los análisis realizados indican, en primer lugar, que la legislación vigente no está ajena a la investigación actual sobre composición escrita: promulga una enseñanza de la composición cuya característica más destacada sea la funcionalidad y, para ello, propone apropiarse de las peculiaridades discursivas y textuales que caracterizan los textos escritos de nuestra lengua al mismo tiempo que no descuida la actividad metacognitiva del alumno mientras escribe; en segundo lugar, que las actividades propuestas en los libros de texto tratan de satisfacer las demandas legislativas a través de dos tipos de actividades: 1) las de producción textual, haciendo especial hincapié en las operaciones cognitivas de planificación, textualización y revisión y 2) las orientadas a aprender las características formales del texto que hay que escribir y de sus condiciones de uso.

Palabras Clave: Composición Escrita, Enseñanza Primaria. 


\section{Introducción}

El concepto de escritura ha seguido el curso marcado por las influencias arrojadas desde el seno de la Psicología Cognitiva, la Pedagogía y la Lingüística; aspectos tales como considerar la escritura con un carácter marcadamente estático, reflejo de una trascripción del lenguaje oral, considerar el acto de escribir como un "arte" de la reproducción y considerar el escrito como un producto han dejado paso a otros aspectos más dinámicos como el considerar la escritura como un proceso de construcción del conocimiento, como una actividad motivacional dirigida hacia la consecución de unos objetivos, el considerarla, en definitiva, como una herramienta de pensamiento, lo que supone aprender a utilizar las palabras para que signifiquen lo que el escritor pretende en cada contexto además de considerarla como un medio de comunicación e interacción que tiene sentido gracias a un contexto socio-cultural compartido entre el que produce el texto y el supuesto receptor del mismo.

Por lo que se refiere al estudio y la investigación aplicada sobre la escritura, se ha pasado de abordar los temas desde paradigmas formales a paradigmas más funcionales, que tienen en cuenta la conducta humana en la interacción social.

Esta transformación en el concepto de la escritura ha tenido su fiel reflejo en la trayectoria seguida por la enseñanza de la expresión escrita, de forma que los enfoques basados en la gramática han dejado paso a enfoques pedagógicos comunicativos, basados en la función de la lengua escrita, en los procesos y en los contenidos.

\section{La escritura como instrumento de autorregulación intelectual y construcción del pensamiento}

Los comienzos: Vygotsky y la escritura como herramienta cultural capaz de controlar los procesos mentales y el comportamiento del hombre

Los modelos actuales sobre composición escrita nos conducen necesariamente a Vygotsky como primer autor quien, a través del análisis efectuado de las diferencias formales y procesuales entre el lenguaje oral (dialógico) y el lenguaje monológico escrito, otorgó a la 
escritura un papel específico como herramienta óptima para desarrollar la función representativa del lenguaje, como instrumento mediador de toma de conciencia, de autorregulación intelectual, desarrollo y construcción del pensamiento. "El lenguaje escrito es una función verbal muy particular. Es el álgebra del lenguaje. Permite al niño acceder al plano abstracto más elevado del lenguaje, reorganizando el sistema psíquico anterior al lenguaje oral” (Vygotsky, 1985, pág. 260)

Vygotsky señala dos variables que modulan el proceso de composición escrita y lo convierten en diferente con respecto al lenguaje hablado. Estas dos variables son:

- Distancia temporal y espacial entre el escritor y el receptor. El lenguaje escrito es como "un discurso-monólogo...con un interlocutor imaginario o sólo figurado" (Vygotsky, 1985, pág. 260).

- Ausencia de un contexto físico y cognitivo compartido entre el productor del texto y el receptor del mismo. "Para el lenguaje escrito nos vemos obligados a crear nosotros mismos las situaciones, más exactamente nos las representamos con el pensamiento. En cierto sentido la utilización del lenguaje escrito supone una relación con la situación fundamentalmente distinta a la que existe en el caso del lenguaje oral, requiere una relación más independiente, más voluntaria, más libre” (Vygotsky, 1985, pág. 261).

Estas dos variables someten al que escribe a un proceso continuo de reflexión con el propósito de que el contenido que él desea transmitir sea el mismo que represente el lector en su mente, (lector que el mismo escritor representa gracias a la elaboración que se ha ido formando en las distintas prácticas comunicativas). Para poder ser interpretado este proceso de recreación obliga al escritor a explicitar su lenguaje con arreglo a una forma circunstanciada que adquiere unas características propias.

Vygotsky (1987) consideraba que el lenguaje escrito promueve una transformación crucial en los procesos mentales, debido, entre otras razones, a las complejas operaciones de descontextualización que deben ejecutarse para construir sentido en ausencia de un interlocutor presente y de la situación comunicativa inmediata. 
En las comunicaciones por escrito las palabras reposan en el significado formal (rigor y precisión en el uso de los términos), se requiere de un número mayor de elementos léxicos que en el lenguaje oral para transmitir una idea, para hacer explícito el contexto físico y el contexto mental con la finalidad de evitar confusiones, ambigüedades e inferencias, existe una diferenciación sintáctica derivada de la necesidad de transmitir coherencia y cohesión en el escrito que es el eje sobre el que rige la organización del texto en los diferentes niveles de la composición escrita: frases, párrafos y textos. Se trata de "un trabajo voluntario sobre los significados de las palabras y su disposición en un cierto orden de sucesión" (Vygotsky, 1985, p. 262). Luria (1980) hablaba de sintaxis explícita al hacer referencia a las estructuras lingüísticas propias del lenguaje escrito.La posibilidad de "volver atrás", de revisar lo escrito favorece el proceso de análisis y síntesis de las propias ideas y la construcción de nuevos aprendizajes.

De la reflexión anterior se desprende que la distinción entre diálogo y lenguaje monológico escrito estriba en el grado de control, implicación y responsabilidad en la construcción del discurso. El proceso de escribir se concibe, desde estos planteamientos, como un problema que hay que resolver y para el cual no tenemos una representación inicial clara y preparada, ni un método estándar de solución. Es esta idea, la de considerar el proceso de escritura semejante al proceso llevado a cabo durante la resolución de problemas sociales, el eje conductor de los distintos modelos actuales de composición escrita. El escritor debe poner en funcionamiento una serie de estrategias con la finalidad de delimitar el problema, inicialmente mal definido y tratar de acotar las posibles vías de solución. La escritura se convierte en un proceso durante el cual el autor debe determinar si el producto que va logrando se ajusta a la representación, que de modo anticipado, se va haciendo de los requisitos que debe reunir el producto final (Bruer, 1997; Hull, 1996; Mateos, 2001).

\section{Las aportaciones de la Psicología Cognitiva}

A partir de los años setenta se desarrolló en Estados Unidos un conjunto de investigaciones sobre el proceso de producción de textos escritos amparadas en el marco de la Psicología Cognitiva. El desencadenante de este cúmulo de investigaciones fue que, a pesar de que los estudiantes tenían buenos conocimientos de gramática y dominaban los diferentes usos de la lengua, sus resultados en composición no eran satisfactorios (Steinberg, 1980). 
Interesaba, pues, conocer las distintas actividades de pensamiento superior que realizaba un escritor (novato, experto, niño o adulto) para componer un texto en el período de tiempo que va desde que se crea una circunstancia social (un motivo) que exige producir un texto (demanda de una tarea propuesta por un profesor, contestación a una carta, deseo de transmitir cierto tipo de información: científica, recreativa, etc., petición de cierta información, son algunos ejemplos) hasta que se concluye el mismo. Los diferentes medios de evaluación que utilizaron fueron: análisis de protocolos en voz alta, análisis de borradores, entrevistas con los escritores, etc., (Bereiter, Burtis y Scardamalia, 1988; Flower y Hayes, 1980). Con esta metodología pretendían llegar a detectar cuáles eran las necesidades de enseñanza-aprendizaje de la composición escrita.

De los análisis de sus observaciones se dedujo que los escritores competentes desarrollan una gran actividad metacognitiva durante el proceso de composición, así pues:

- Hacen una representación de la tarea teniendo en cuenta la audiencia, la función comunicativa y el contexto.

- Revisan el texto para ver si se adapta a los objetivos planteados y “dice" lo que ellos quieren transmitir.

El comportamiento de los escritores menos competentes contrasta con el de los anteriores, dedicando menos tiempo a los subprocesos de planificación y revisión de sus escritos. Este tipo de investigaciones culminó con la elaboración de un modelo cognitivo sobre la composición escrita elaborado por J. Hayes y L. Flower (1980) y con la descripción, por parte de Scardamalia y Bereiter (1985), Bereiter y Scardamalia (1987) y Bereiter et al. (1988), de dos tipos de estrategias cognitivas distintas utilizadas habitualmente por los estudiantes durante la producción de textos escritos: estrategias de decir el conocimiento y estrategias de construir el conocimiento; éstas últimas, según estos autores, son las verdaderas prácticas escritoras generadoras de aprendizaje.

Cabe destacar, de lo comentado hasta el momento, que basándose en el soporte teórico del modelo presentado por Hayes y Flower (1980) y apoyándose en las estrategias utilizadas en construir el conocimiento descritas por C. Bereiter y M. Scardamalia (1987), se han realizado numerosas propuestas didácticas sobre la enseñanza de la composición escrita basada en los procesos, y que los componentes fundamentales del mismo aparecen como ejes fundamentales en las explicaciones sobre las operaciones cognitivas (estrategias para ser 
utilizadas por uno mismo) que se llevan a cabo cuando se produce un texto (Cooper y Matsuhashi, 1983; De Beaugrande, 1984; Martlew, 1983). Por esta razón nos parece conveniente revisar, sin ánimo de exhaustividad, las principales contribuciones de dichos autores.

Un problema retórico: Flower y Hayes (1980) y Flower (1981)

Flower y Hayes (1980) y Flower (1981) conciben la escritura como un problema retórico, "autodefinido", ya que es el propio escritor quien, dentro de unos determinados parámetros, decide la tarea que debe resolver. La escritura, pues, puede analizarse desde un punto de vista psicológico en términos de procesos de resolución de problemas. Los autores argumentan que el punto esencial del proceso se sitúa, precisamente, en la definición del problema retórico que el escritor se plantea e intenta resolver mediante la producción del texto. El modelo propuesto por Flower y Hayes $(1980 ; 1981)$ tenía tres componentes importantes:

1) El primero es el entorno de la tarea o situación de comunicación. Este componente incluye todos aquellos factores que influyen en la tarea de la escritura pero que están fuera del propio escritor. Estos factores son de tipo social (demandas de un trabajo de escritura por parte de un profesor) y físicos (texto que el autor ha escrito hasta el momento).

2) El segundo componente abarca todos los procesos cognitivos implicados en la escritura: la planificación (decidir qué decir y cómo decirlo), la traducción (que convierte los planes en textos escritos) y la revisión (mejorar o corregir el texto existente). Estos procesos cognitivos se presentan de forma recursiva a lo largo del proceso de composición y son controlados por un monitor que dirige y orienta el momento y el orden en que conviene activarlos.

3) El tercer componente era la memoria a largo plazo del escritor, que incluía el conocimiento de los temas, el conocimiento de la audiencia y del género textual e interactuaba con cada uno de los tres procesos cognitivos de escritura (planificación, traducción y revisión). 
El funcionamiento del modelo consistía en lo siguiente: la construcción del problema retórico, definido como propósito o intención que guía la producción del texto, determina la planificación que lleva a cabo el escritor y pone en funcionamiento distintos subprocesos: generar o buscar ideas en la memoria a largo plazo, organizar esas ideas y concretar y formular los objetivos del texto.

Los autores destacan las operaciones metacognitivas que el escritor pone en marcha durante esta construcción del problema teniendo en cuenta a la audiencia y tratando de que su texto tenga el significado que él desea transmitir. Para los autores anteriores, un "buen escritor" sería aquel que elaborase una compleja red de objetivos para incidir sobre el lector y una red coherente de ideas, que le condujesen a "formar nuevos conceptos, y hasta quizá a reestructurar su antiguo conocimiento sobre el tema" (citado en Miras, 2000, p. 71).

Una de las críticas más conocidas que se le ha achacado a este modelo es que, a pesar de que los autores defienden un carácter recursivo en las operaciones cognitivas implicadas durante el proceso de composición escrita, se aprecia cierto aire de secuencialidad. Otra de las críticas más compartidas es el excesivo peso otorgado al proceso de planificación y la falta de concreción de las operaciones implicadas en el proceso de textualización, y por último, parece que del modelo se desprende la existencia de una sola manera competente de escribir textos, aunque son los propios autores los que argumentan que aunque existe una gran dificultad de componer textos sin llevar a cabo un exhaustivo proceso de planificación, hay escritores que pueden hacerlo escribiendo lo que se les pasa por la cabeza y en el orden en que le van surgiendo esas ideas apoyándose en el texto que llevan producido.

Del “decir el conocimiento” a "construirlo”: Bereiter y Scardamalia $(1987,1988)$

Como ya indicáramos en párrafos precedentes, Bereiter y Scardamalia (1987) concluyeron, después de reiterados estudios experimentales, que los escritores utilizan diferentes estrategias cognitivas en sus producciones escritas que ellos calificaron como decir el conocimiento y construir o transformar el conocimiento. Según estos autores las estrategias cognitivas del primer grupo -decir el conocimiento-son de tipo secuencial: "pensar-decirpensar-decir...". El escritor planifica el contenido y escribe sobre la marcha, paso a paso, relacionando cada frase con la anterior y con el tema general del escrito que produce, pero no 
relaciona los contenidos que escribe con las exigencias de la situación comunicativa y no elabora una imagen operativa de dicha situación. El problema que debe resolver el escritor está estrechamente relacionado con la producción de un texto delimitado por un tema y por un tipo de género literario. Este tipo de comportamiento mientras se escribe fue detectado, a través de reiteradas investigaciones por los autores, en una gran mayoría de estudiantes y, según ellos, es una forma de adaptación al éxito en situaciones escolares donde el tema de los escritos está relacionado con contenidos escolares que ellos deben dominar o sobre contenidos elegidos libremente por ellos mismos y el objetivo de la escritura se reduce a satisfacer los requerimientos del profesor. De esta manera, cuando un alumno domina el contenido sobre el que tiene que componer y además domina las distintas estructuras textuales, conseguirá los resultados requeridos por el profesor. Pero esta forma de escribir que presta poca atención a los objetivos, a la planificación y al problema de selección de contenidos, elimina la retroalimentación del proceso de escritura respecto al conocimiento y comprensión del escritor. En palabras de los autores "para el que dice lo que sabe, la escritura es un medio de comunicación, pero no una herramienta del pensamiento" (Bereiter y Scardamalia, 1993, pág. $56)$.

A través de las estrategias cognitivas de transformar el conocimiento, el escritor interrelaciona, gracias a un proceso dialéctico, los contenidos temáticos sobre los que escribe, es decir el espacio problema de contenido (el qué decir) con el espacio problema retórico (con qué intención y cómo decirlo), lo cual le lleva a reelaborar dichos contenidos y a transformarlos para adecuarse a la situación. El proceso dialéctico surge cuando la solución a los problemas retóricos que se le plantean al escritor da lugar a un cambio en sus conocimientos (p. ej., el problema para elegir un tema adecuado lleva al escritor a considerar los diversos matices de un concepto y a ampliar su comprensión del mismo) y cuando el escritor percibe que un cambio en sus conocimientos genera en el espacio retórico un problema significativo que debe intentar resolver (p. ej., al darse cuenta de que un argumento está estrechamente relacionado con otro, el escritor considera la estructura global del apartado) (Miras, 2000). A través de estas estrategias cognitivas se vislumbra el carácter recursivo de las distintas operaciones que el escritor lleva a cabo a lo largo del proceso y las complejas relaciones que se establecen entre los objetivos del escritor y el producto que resulta de la textualización. El escritor competente que utiliza estrategias cognitivas de transformar el conocimiento utiliza su conocimiento del contenido y su conocimiento 
discursivo para producir el texto, pero, a su vez, la escritura que produce influye en sus conocimientos, tanto conceptuales como discursivos.

Aspectos socioculturales, cognitivos y emocionales durante el proceso de composición: John R. Hayes (1996).

John R. Hayes (1996) actualiza el modelo de Hayes y Flower (1980) y ofrece un marco de análisis de la composición más amplio que integra aspectos socioculturales, cognitivos y emocionales. El actual modelo destaca dos componentes esenciales sobre los que gira todo el proceso de composición escrita: el entorno de la tarea o componente sociocultural $\mathrm{y}$ el individuo.

1) El entorno de la tarea está configurado, al igual que en el anterior modelo, por un entorno social, que incluye la audiencia y los posibles colaboradores y por un entorno físico que incluye el texto producido hasta el momento y el medio de composición utilizado (procesador de texto utilizado, composición manuscrita, etc.)

2) El componente individual viene configurado por el triángulo interrelacionado entre los procesos motivacionales (metas, predisposiciones, creencias y actitudes y la valoración de costes/beneficios), cognitivos (interpretación de textos, reflexión y producción del texto) y conceptuales representados por la memoria activa (fonológica, semántica y visoespacial) y la memoria a largo plazo (esquemas de trabajo, conocimiento del tema, conocimiento lingüístico y conocimiento del género). Estos procesos mantienen un paralelismo con los planos del aprendizaje: valores, destrezas y conceptos (Cassany, 1999).

Hayes (1996) entiende la escritura un acto comunicativo que requiere de un contexto socio-cultural y de un medio, como una actividad generativa que requiere motivación y como una actividad intelectual que exige procesos cognitivos y memoria.

Los aspectos a destacar del presente modelo como propios del escritor individual son:

- El énfasis que le otorga a la memoria activa durante el acto de escribir.

- El papel modulador de la emoción y la motivación durante el proceso. 
- La reestructuración de los procesos cognitivos que intervienen en el acto de escribir.

- La incorporación del lenguaje oral durante el proceso.

El presente modelo asume que todos los procesos tienen acceso a la memoria activa.

Para describir este tipo de memoria en la escritura el autor se basó en el modelo general de Baddeley y la concibió como un recurso limitado que es utilizado tanto para almacenar información como para desarrollar los procesos cognitivos y que consta de varias memorias específicas: fonológica, semántica y visoespacial. La inclusión de las representaciones visoespaciales está justificada, según Hayes, porque las publicaciones científicas, los libros escolares, las revistas y otros materiales impresos incluyen gráficos, tablas y dibujos que son esenciales para la comprensión del texto y, por tanto, para entender esos textos es necesario, aunque no suficiente, comprender esos rasgos visuales y espaciales.

Otro aspecto a destacar del actual modelo es que reserva un lugar significativo para la motivación y la emoción en el proceso de composición, y su inclusión la justifica en base a varias investigaciones que demuestran la influencia de estos factores sobre la escritura. Hayes analiza cuatro áreas que considera de especial importancia para la escritura:

1) La naturaleza de la motivación en la escritura. Este tema ha sido analizado en relación al comportamiento a largo plazo de los individuos a la hora de realizar diferentes actividades. Relacionando motivación y creencias, diferentes investigaciones han puesto de manifiesto cómo las creencias que tiene una persona sobre la escritura influyen en su disposición para escribir.

2) Interacción entre fines. Los escritores, normalmente, cuando escriben tienen más de un objetivo al escribir y adecuan sus textos después de haber establecido un equilibrio entre los fines divergentes. Los fines múltiples interactúan entre sí para determinar el curso de la acción.

3) La elección entre métodos. El autor, según el grado de beneficio (propósito, interés) que estima obtener del texto, decide qué grado de coste (esfuerzo, dedicación) está dispuesto a emplear y selecciona las estrategias más 
adecuadas. De esta manera, la motivación puede ser entendida como si moldeara el curso de la acción a través de un mecanismo de coste-beneficio.

4) Respuestas emocionales en la lectura y la escritura. Las respuestas emocionales están moduladas por las creencias o actitudes sobre la escritura. Creencias irracionales del tipo "la escritura es un don", o las atribuciones negativas "yo soy mal escritor", conducen con mayor probabilidad a experimentar ante la escritura respuestas de ansiedad.

Con respecto a las funciones cognitivas primarias implicadas en la escritura, Hayes propone las siguientes: la interpretación de textos, la reflexión y la producción de textos.

La interpretación de textos la define como una función que se encarga de crear representaciones internas a partir de inputs lingüísticos y gráficos. Para interpretar los textos es necesario leer, escuchar y observar gráficos. Con respecto a la reflexión, el autor la define como una actividad que opera sobre las representaciones internas para producir otras representaciones internas nuevas. Analiza, descompone, reelabora las representaciones creadas a partir de inputs lingüísticos o gráficos para crear nuevas versiones que pueden generar productos, outputs de salida. La reflexión es posible gracias a procesos tales como resolución de problemas, la toma de decisiones y la inferencia. Por último, con respecto a la producción textual, la concibe como una función que lleva las representaciones internas al contexto del entorno de la tarea y genera productos escritos, gráficos o fónicos.

Por último, Hayes incorpora el lenguaje oral en su modelo de escritura y sostiene su postura al indicar que el lenguaje hablado puede proporcionar contribuciones valiosas al proceso de composición bajo la forma de comentarios editoriales e informaciones sobre los contenidos. Cassany (1999) pone como ejemplo cómo numerosos datos sobre el contexto de una tarea de escritura se pueden vehicular oralmente, por lo que el autor ha de comprender y representarse la tarea a partir de informaciones orales. También dos o más aprendices en situación de composición colaborativa pueden vocalizar lo que están escribiendo antes de anotarlo, como estrategia de evaluación compartida, o incluso, el compositor puede ir vocalizando lo que escribe con la finalidad de ir percibiendo su modulación. En este aspecto introducido en el modelo de Hayes se deja entrever claramente el pensamiento Vygotskiano 
en el sentido de que el significado se construye, según Vygotsky, mediante la interacción lingüística con los demás, considerado el lenguaje como una herramienta para fomentar el pensamiento y el saber.

En el punto siguiente analizaremos cómo han sido tenidas en cuenta las conclusiones derivadas de la investigación sobre composición escrita a la hora de elaborar la legislación educativa.

\section{Presencia de la investigación actual en la legislación educativa vigente: Real Decreto 1006/1991 y Real Decreto 1344/1991}

El Real Decreto 1006/1991 de 14 de junio de 1991, publicado en el B.O.E. 152, miércoles 26 de junio de 1991, establece las enseñanzas mínimas para la educación primaria de todo el Estado. El área de lengua castellana y literatura es una de las cinco áreas que configuran esta etapa educativa. Este real decreto aparece recogido en un anexo al núm. 152 y el área de lengua castellana y literatura se detalla entre las páginas 16 y 21.

En el Real Decreto 1344/1991 de 6 de septiembre, publicado en el B.O.E. 220, viernes 13 de septiembre de 1991, se establece el currículo para educación primaria en el ámbito de competencia del Ministerio de Educación y Ciencia. El currículo para el área de lengua castellana y literatura se desarrolla en el suplemento al núm. 220 entre las páginas 22 y 27.

En la introducción al área se establecen los principios teóricos que la definen. Se analizan las relaciones entre lenguaje y pensamiento, resaltando la importancia del lenguaje interior como operación cognitiva fundamental para la comunicación con uno mismo, para analizar los problemas, para organizar la información de que se dispone, para elaborar planes y en el proceso de toma de decisiones; en definitiva, queda patente la idea de que es a través de los procesos de reflexión que el lenguaje interior hace posible, cómo se regula y se orienta la actividad del ser humano. Se resaltan la función comunicativa y representacional del lenguaje. Aprender lengua es aprender significados, cultura. Estos planteamientos teóricos que fundamentan las enseñanzas mínimas y el currículo del Área de Lengua Castellana y Literatura para la Educación Primaria fueron los principios que introdujo Vygotsky en su 
célebre obra Pensamiento y Lenguaje (1977) donde desarrolló su teoría "histórico-cultural" de las funciones psicológicas superiores y traslucen una concepción funcional de la lengua de donde se deriva la importancia concedida al discurso como herramienta comunicativa donde convergen y se cumplen las diferentes funciones del lenguaje, la importancia concedida a las tipologías de textos con sus funciones propias y con sus características lingüísticas específicas y la importancia concedida al conocimiento de las convenciones socio-culturales: fonológicas, morfosintácticas y de discurso. A este respecto dicen los Reales Decretos 1334/1991 y 1006/1991 en la introducción al área:

"La educación y el aprendizaje en esta área han de atender a esa múltiple función de la lengua, de comunicación y de representación, así como de regulación del comportamiento ajeno y propio. Ha de incluir también una iniciación al texto literario como manifestación de la funcionalidad de la lengua" (1334/1991, pág. 22).

En esa introducción teórica se resalta también el papel de la comprensión y la expresión como los procesos básicos de la función comunicativa. Educar en la comprensión del lenguaje significa favorecer el desarrollo de estrategias que permitan interpretar, relacionar y valorar la información y los mensajes que se reciben en la vida cotidiana. Los procesos cognitivos de interpretación y de reflexión de los que habla Hayes (1996) serían los procesos últimos que hacen posible la comprensión. En cuanto al proceso de expresión, coincide con el de producción textual señalado por el citado autor.

La referencia concreta al tema de la composición escrita se desarrolla en los apartados siguientes.

Real Decreto 1006/1991 donde se establecen las enseñanzas mínimas.

Las enseñanzas mínimas o aspectos básicos del currículo establecen los siguientes objetivos generales en materia de composición escrita:

81. Reflexionar sobre el uso de la lengua, comenzando a establecer relaciones entre los aspectos formales y los contextos e intenciones comunicativas a los que responden para mejorar las propias producciones.

10. Utilizar la lengua oralmente y por escrito como instrumento de aprendizaje y planificación de la actividad mediante el recurso a procedimientos (discusión, esquema, 
guión, resumen, notas) que facilitan la elaboración y anticipación de alternativas de acción, la memorización de informaciones y la recapitulación y revisión del proceso seguida.

En el apartado de contenidos la referencia concreta al tema de la composición se hace en los apartados de Usos y formas de la comunicación escrita y Análisis y reflexión sobre la lengua. Con respecto al primer apartado, los contenidos declarativos que concretan esa referencia son:

3. El texto escrito como fuente de placer, de información y aprendizaje, como medio de enriquecimiento lingüístico y personal, y como expresión de valores sociales y culturales.

4. Diversidad de textos escritos. Textos literarios.

5. Formas básicas adecuadas a las diferentes situaciones e intenciones comunicativas.

6. Estructuras propias de los diferentes tipos de texto (narración, descripción, exposición, argumentación, etc.) y formas elementales que dan cohesión al texto.

En cuanto a los contenidos procedimentales, podemos destacar:

9. Utilización de diversas fuentes de información escrita para satisfacer necesidades concretas de información.

10. Producción de textos escritos empleando formas adecuadas a distintas situaciones e intenciones comunicativas, estructurando sus partes y utilizando formas elementales que den cohesión al texto, y revisión de los mismos.

11. Utilización de textos de apoyo en el proceso de producción de un texto escrito.

12. Exploración de las posibilidades expresivas de la lengua escrita a partir de la observación y análisis de textos modelo.

13. Producción de textos escritos para recoger y organizar la información, para planificar experiencias, para elaborar alternativas y anticipar soluciones, para memorizar mensajes, etcétera.

Los contenidos actitudinales:

1. Valoración de la lengua escrita como medio de información y de transmisión de cultura, y como instrumento para planificar y realizar tareas concretas.

2. Valoración de la lectura y la escritura como fuente de placer y diversión.

3. Actitud crítica ante los mensajes transmitidos por los textos escritos, mostrando especial sensibilidad hacia los que suponen una discriminación social, sexual, racial, etcétera. 
4. Autoexigencia en la realización de las propias producciones y valoración de la claridad, el orden y la limpieza en los textos para lograr una mejor comunicación.

En el apartado Análisis y reflexión sobre la lengua, la referencia concreta al tema de la composición se plantea a través de los contenidos declarativos siguientes:

2. Estructuras básicas de la lengua (del texto, de la oración, y de la palabra) y su funcionamiento dentro del discurso.

3. Vocabulario.

4. Ortografía.

En los contenidos procedimentales siguientes:

2. Observación de regularidades sintácticas, morfológicas y ortográficas en las producciones verbales.

3. Formulación y comprobación de conjeturas sencillas sobre el funcionamiento de las estructuras básicas de la lengua.

4. Verbalización de las observaciones realizadas, identificando las normas sintácticas, morfológicas y ortográficas básicas.

Y en los contenidos actitudinales siguientes:

1. Aprecio por la calidad de los textos propios y ajenos (su adecuación, coherencia y corrección) como medio para asegurar una comunicación fluida y clara.

2. Aceptación y respeto por las normas básicas de la lengua.

3. Interés por la búsqueda de cauces comunicativos personales y creativos en el uso de la lengua.

Los criterios de evaluación en materia de composición escrita son:

10. Elaborar textos escritos de diferente tipo (narraciones, descripciones, informes sencillos, etc.) empleando la estructura textual correspondiente y utilizando los procedimientos básicos que dan cohesión al texto (usar nexos, mantener el tiempo verbal, puntuar adecuadamente, etc.). Este criterio trata de verificar que los alumnos son capaces de expresarse por escrito de forma coherente. Se atiende a la producción de diferentes tipos de texto de acuerdo con la estructura correspondiente y a los procedimientos fundamentales que dan cohesión a sus distintos elementos. Se abarcan textos de diverso tipo. 
11. Incorporar a las propias producciones las normas ortográficas y emplear apoyos que, en el proceso de producción de un texto, permitan resolver dudas ortográficas (diccionario, fichas de consulta, libretas de palabras...). Este criterio pretende evaluar la utilización de la ortografía en la producción de textos.

12. Producir textos escritos de acuerdo con un guión o plan previamente establecido, valorar la adecuación del producto al plan inicial mediante una discusión en grupo o con el profesor e introducir las modificaciones oportunas. Mediante este criterio se pretende verificar que la producción de textos escritos se realiza de acuerdo con los pasos de este proceso (planificación, revisión, incorporación de nuevas aportaciones).

13. Utilizar producciones escritas propias y ajenas (notas, listas, guiones sencillos, resúmenes, etc.) para organizar y llevar a cabo tareas concretas individuales o colectivas. Este criterio de evaluación presta atención a la utilización de la lengua en la regulación y organización de la propia actividad.

Real Decreto 1334/1991 donde se establece el currículo para la educación primaria

El currículo del área de lengua española de la educación primaria está compuesto por el conjunto de objetivos, contenidos, criterios de evaluación y la metodología que han de regular la práctica docente en dicha área en este nivel educativo. A través de estos elementos se manifiestan los propósitos educativos del currículo. El currículo requiere una ulterior concreción por parte de los profesores en diferentes momentos.

Los objetivos generales así como los criterios de evaluación son los regulados por el Real Decreto 1006/1991 en el que se establecen las enseñanzas mínimas. Los contenidos recogen los incluidos en las enseñanzas mínimas del citado Real Decreto y los completan hasta definir la integridad del currículo.

La enseñanza de la composición escrita está contemplada dentro de los contenidos del apartado Usos y formas de comunicación escrita y del apartado Análisis y reflexión sobre la lengua. Con respecto al primer apartado, en el apartado de conceptos, cabe destacar los puntos que hacen referencia a los modelos textuales y las convenciones sociales de uso de la lengua:

1. Necesidades y situaciones de comunicación escrita en el medio habitual del alumnado. 
- El texto escrito como fuente de placer, de información y aprendizaje, como medio de enriquecimiento lingüístico y personal, y como expresión de valores sociales y culturales.

2. Características de la situación de comunicación, intenciones comunicativas y formas adecuadas.

- Características de la situación de comunicación: número y tipo de interlocutores, distancia en el espacio y en el tiempo, etc.

- Intenciones comunicativas: expresar sentimientos, narrar, describir, informar, convencer, imaginar, jugar con las palabras, etc.

- Formas básicas adecuadas a las distintas situaciones e intenciones comunicativas: vocabulario, estructura del texto y de la oración, etc.

3. Relaciones entre la lengua oral y la lengua escrita.

- Correspondencias fonema-grafía y sus agrupaciones

- Acento, entonación y pausas. Tildes y signos de puntuación.

- Otros aspectos de la escritura y de los textos escritos, dirección y sentido de la escritura, linealidad, distribución en el papel, separación de palabras, márgenes, función de las ilustraciones, etc.

4. Diversidad de textos en la comunicación escrita.

- Textos literarios: poemas, cuentos, etc.

- Otros textos escritos, folletos, prospectos, recetas, rótulos, publicidad estática, etc.

5. Estructuras propias de los diferentes tipos de texto (narración, descripción, exposición, argumentación, etc.) y formas elementales que dan cohesión al texto.

En el apartado de procedimientos cabe destacar los puntos siguientes:

11. Producción de textos escritos atendiendo a diferentes situaciones e intenciones comunicativas.

- Elección de formas adecuadas a las características de la situación de comunicación y a la intención pretendida.

- Organización del texto de acuerdo con la estructura textual correspondiente y uso de formas básicas que dan cohesión al texto.

- Utilización correcta de las normas de la escritura. 
12. Planificación y revisión de los textos escritos, comprobando que la forma se adecua a la intención deseada y a las características de la situación de comunicación.

13. Utilización de textos de apoyo en el proceso de producción de un texto escrito (diccionario, fichas de consulta, libretas ortográficas, textos modelo, manuales sencillos, etc.).

14. Exploración de las posibilidades expresivas de la lengua escrita a partir de la observación y análisis de textos modelo.

15. Producción de textos escritos (resúmenes, guiones, esquemas, fichas de recogida de información, cuestionarios, etc.) para recoger y organizar la información, para planificar experiencias, para elaborar alternativas y anticipar soluciones, para memorizar mensajes, etc.

En el apartado Análisis y reflexión sobre la propia lengua, el conocimiento declarativo específico en cuanto a composición escrita se refiere está relacionado con las tramas textuales y con las convencionalidades ortográficas que el alumno debe dominar para poder usar los textos escritos que mejor se adecuen a sus intenciones comunicativas. Este conocimiento declarativo está recogido en los siguientes puntos:

2. Estructuras básicas de la lengua (del texto, de la oración y de la palabra) y su funcionamiento dentro del discurso.

- Tipo de texto y estructuras propias de cada uno (narración, descripción, argumentación etc.)

3. Vocabulario (sentido propio y figurado, modismos, etc.)

4. Ortografía (palabra, oración y texto).

Los contenidos procedimentales están recogidos en los siguientes puntos:

2. Observación de regularidades sintácticas, morfológicas y ortográficas en las producciones verbales.

3. Formulación y comprobación de conjeturas sencillas sobre el funcionamiento da las estructuras básicas de la lengua.

4. Verbalización de las observaciones realizadas, identificando las normas sintácticas, morfológicas y ortográficas básicas y empleando una terminología adecuada.

Los contenidos actitudinales están recogidos en los siguientes puntos:

1. Aprecio por la calidad de los textos propios y ajenos (su adecuación, coherencia y corrección) como medio para asegurar una comunicación fluida y clara.

2. Aceptación y respeto por las normas básicas de la lengua. 
3. Interés por la búsqueda de cauces comunicativos personales y creativos en el uso de la lengua.

La valoración de la lengua oral como instrumento para satisfacer las propias necesidades de comunicación y para, planificar y realizar tareas concretas, es una actitud que coincide con el cuarto aspecto que introduce Hayes (1996) -incorporación del lenguaje oral durante el proceso de composición- y fiel reflejo de la influencia vygotskyana.

A través de los diferentes conceptos o conocimiento declarativo se pretende engrosar el cúmulo de conocimientos necesarios que se irán integrando en las diferentes memorias del sujeto con la finalidad de ser usados dependiendo de la intención comunicativa del escritor y de las demandas de la situación.

El conocimiento procedimental se refiere al conocimiento que tiene el individuo acerca de la ejecución de las tareas. Así por ejemplo, cuando un escritor experto se enfrenta a la tarea de escribir utiliza de manera automática recursos lingüísticos, es decir, actúa en congruencia con el saber declarativo. Mediante estos procedimientos se pretende que los alumnos aprendan estrategias específicas para llevar a cabo tareas regulando sus propios procesos.

Cada uno de los usos requiere del escritor conocimientos para escribir un texto adecuado a su función social y comunicativa a su contexto.

En los apartados anteriores, de procedimientos y de criterios de evaluación podemos observar la importancia otorgada a los procesos cognitivos durante las actividades de composición apuntados por Hayes (1996) en forma de estrategias, los cuales interactúan con los diferentes conocimientos almacenados en la memoria a largo plazo y recuperados, según las intenciones del compositor.

Y por último, las recomendaciones metodológicas que se establecen en el currículo tienen un claro matiz constructivista que impregna toda la legislación educativa vigente y giran en torno a los siguientes ejes:

- Papel activo del alumno durante el proceso de enseñanza- aprendizaje.

- Profesor guía: mediador de los aprendizajes ofreciendo diferentes oportunidades a los alumnos para que interioricen los contenidos.

- Enseñanza de tipo funcional.

- Potenciación del conocimiento de los códigos convencionales e instrumentos de la cultura. 
- Consideración de la evaluación como un proceso continuo que forma parte del propio proceso de aprendizaje.

Hemos descrito las incorporaciones de la investigación sobre composición escrita a la legislación educativa y ahora pasamos a analizar si estas recomendaciones son recogidas en los textos que se utilizan para la enseñanza de la misma.

\section{Análisis de los libros de textos}

Para realizar este estudio hemos revisado los libros de texto de lengua castellana de la editorial Santillana correspondientes a los seis niveles que componen la enseñanza obligatoria primaria. La razón de analizar los libros de textos de esta editorial no es otra que la de ser la más utilizada en los Centros Públicos de la Comunidad Autónoma de Extremadura: de un total de 398 Colegios repartidos por toda la Comunidad, 5 son privados, 63 son privados/concertados y 330 son públicos. De entre los públicos, 8 son preferentemente de sordos y 1 preferentemente de deficientes motóricos (datos extraidos de la Guía de Servicios Educativos de Extremadura 2003-2004). De un total de 321 centros públicos el 61,68\% de ellos utilizan la mencionada editorial para desarrollar los contenidos de Lengua Castellana y Literatura. (según datos obtenidos a través de contacto telefónico).

La estructura de los libros responde al siguiente esquema de trabajo:

- Anunciar al alumno lo que va a aprender en cada unidad del libro "En esta unidad vas a aprender a hacer un resumen"

- Realizar unas cuestiones previas para sondear y recuperar los conocimientos anteriores sobre el objeto de aprendizaje. "Qué crees que es un resumen?

- Partiendo de un modelo textual, leerlo fijándose en algunos detalles y responder a cuestiones relacionadas con el tema (identificar las partes del cuento, por ej.).

- Leer, observar (imágenes y textos), escuchar (relatos escritos, a otros compañeros, al profesor) y hablar en grupo.

- Pensar sobre lo leído, observado, escuchado y debatido (en el sentido de reflexionar) 
- Instruir al alumno sobre aspectos relacionados con el objeto de enseñanzaaprendizaje (las partes de que se compone un cuento, por ej.)

- Escribir (textualizar).

- Al final de cada tema hay una revisión final (evaluación) donde se insta a reflexionar a los alumnos sobre lo que se ha aprendido en la unidad, cómo se ha aprendido y para qué puede utilizar ese aprendizaje en sucesivas ocasiones.

La organización de los libros, como mediadores en la construcción del conocimiento del niño está regida por la célebre tesis de Vygostsky: "transformación de los fenómenos interpsíquicos en fenómenos intrapsíquicos” (Vygotsky, 1982-1984, Vol. II, p. 56).

\section{Leer, observar, escuchar y pensar: el valor de la memoria para la interpretación de los textos y los procesos de reflexión}

A través de la lectura, la observación y la escucha (partiendo siempre de un modelo textual acompañado de una o unas imágenes alusivas al tema) se pretende que se elaboren contenidos y se asimilen estructuras o esquemas textuales así como pautas convencionales de escritura: ortográficas, tipos de discurso, etc. Los mapas cognitivos o esquemas configuran el contenido de las distintas memorias que guiarán después tanto los procesos de expresión como los de comprensión del discurso (oral o escrito).

La interacción verbal en grupo permite exponer puntos de vistas propios sobre un determinado tema, permite reorganizar, matizar y perfilar tanto el contenido como la forma que tendrá después el escrito.

Antes de escribir se insta al alumno a buscar información (preguntando a un adulto, buscando en el periódico, buscando en el diccionario, en una enciclopedia, etc.) y a pensar sobre lo que se le pregunta antes de escribirlo (a indagar sobre posibles vías de solución para el problema retórico planteado). Toda esta actividad necesaria antes de escribir hace posible el proceso descrito por Hayes (1996) como interpretación de textos. 
Qué se le pide a los niños que escriban: producción textual

Al niño se le pide que escriba textos que tengan un contexto que le dé sentido: "Vas a escribir una carta a una amiga que hace tiempo que no ves para comunicarle algo que te haya sucedido recientemente", por ejemplo. Son los llamados textos basados en los ámbitos de uso:

Ámbito personal: escribir un diario, una carta (a un amigo, de reclamación, de petición a una autoridad), notas, una receta de cocina, hacer un pedido, escribir un anuncio, etc.

- Ámbito familiar y de amistades: escribir mensajes, escribir una invitación, etc.

- Ámbito académico: escribir un cuento (atendiendo a diferentes consignas), reescribir un cuento (atendiendo a diferentes consignas: "Qué pasaría si el protagonista hubiese sido..., hecho..., etc."), escribir una historia relacionando los personajes que aparecen en un dibujo, inventar poesías, inventar adivinanzas, escribir una biografía, confeccionar fichas de libros leídos, etc.

- Ámbito social: confeccionar un mural, hacer un periódico, escribir un cómic, escribir un folleto informativo o explicativo, etc.

Como podemos observar cada una de las tipologías de texto que el alumno debe saber usar responde a una determinada función de la lengua: informativa (carta, diario, artículo de opinión, noticia, etc.), expresiva (carta, diario, etc.), literaria (cuento, poesías, etc.) y apelativa (nota de aviso, folleto, receta, instrucciones de uso, solicitud, etc.).

Para saber usar un determinado tipo de texto que responda a una determinada intención comunicativa, se necesita dominar diferentes tramas textuales, de ahí que se ejercite al alumno en las técnicas conversacionales, descriptivas, narrativas, expositivas, argumentativas, así se le pide que escriban textos de la siguiente manera:

- Textos de conversación: escribir un cuento con diálogos.

- De descripción: describir personas, describir objetos, describir una escena, describir un paisaje, el interior de un lugar

- De narración: escribir un cuento, narrar un hecho, contar un noticia. 
- De exposición: preparar una exposición oral, dar instrucciones, analizar un tema, argumentar, dar un informe, hacer una reclamación,

- De retórica: escribir poesías.

Este tipo de actividades de producción textual están encaminadas al aprendizaje y ejercitación de ciertas características de los géneros discursivos.

\section{Cómo escribir: el papel de las pautas}

Durante el proceso de textualización se le atribuye un papel muy importante al uso de "pautas". La pauta presentada a los alumnos como guía en su proceso de composición de los diferentes textos puede ser considerada un instrumento que ayuda a desencadenar diversas operaciones cognitivas. Trata de incidir en los procesos cognitivos incluidos en el segundo componente del modelo de composición presentado por Flower y Hayes (1980): planificación, redacción y revisión (o sobre lo que se ha llamado "procesos cognitivos" dentro de los aspectos a destacar en relación al individuo en el modelo actual de Hayes (1996). La terminología utilizada es la misma que la utilizada por los autores en el modelo de 1980.

Estas pautas introducidas en los procesos de planificación, redacción y revisión del texto actúan como mediadores de procesos de autorregulación en las situaciones de aprendizaje y constituyen un elemento clave para desencadenar y guiar el proceso de regulación que culminará con la producción del texto y la construcción del conocimiento. Las indicaciones a seguir en cada uno de los procesos en forma de lista (Por ej. en la pauta presentada para aprender a escribir notas, tenemos: 1) planificación: motivo de la nota; ¿para qué?, 2) redacción: escribe; no olvides incluir estos datos: a quién va dirigida, quién eres tú y qué quieres decir 3) revisión: revisa las faltas de ortografía, nombres propios con mayúscula, etc.) se asemejan a las estrategias de escritura utilizadas por Bereiter y Sacardamalia (1993) con la finalidad de inyectar más pensamiento en el proceso de escribir y son muy utilizadas en el ámbito de la evaluación formativa en la enseñanza de la composición escrita (Camps, 1993).

Tanto la estructura como el desarrollo del libro están en consonancia con los planteamientos funcionalistas recogidos en la legislación vigente dentro del área de Lengua 
Castellana y Literatura, ejes vectores sobre qué se debe enseñar y cómo se debe enseñar la composición escrita.

El objetivo general de cada lección, en cuanto a composición escrita se refiere, es aprender a realizar una función determinada en la lengua castellana (tipologías de textos en este caso).

Los contenidos hacen referencia a los conocimientos necesarios para poder hacer uso de las convenciones socio-culturales de nuestra lengua. Estos conocimientos serán almacenados en la memoria a largo plazo y serán recuperados cada vez que el compositor los necesite.

En cuanto a las estrategias utilizadas, se destacan los siguientes aspectos:

- Papel de los procesos de análisis y síntesis de modelos textuales a través de la lectura y la observación.

- El diálogo con uno mismo (autorregulación), con los compañeros y con el profesor como vía para internalizar los diferentes esquemas textuales.

\section{Conclusiones}

"Es indudable que, en múltiples aspectos, Vygotsky se adelantó considerablemente a nuestra propia época" (Rivière, 1984, pág. 120). Sus reflexiones sobre la escritura como un instrumento cultural que se arraiga en el individuo y se convierte en un instrumento individual privado están presentes en los modelos teóricos sobre composición escrita que hemos descrito en este artículo: Hayes y Flower (1980), las contribuciones de Bereiter y Scardamalia (1987) y la revisión de Hayes (1996).

Existe un acuerdo generalizado en considerar la escritura como un proceso cognitivo que evidencia un alto componente de regulación metacognitiva, de ahí que la investigación actual sobre composición escrita y la intervención psicoeducativa (Allal, 1993; Bereiter y Scardamalia,1993; Camps, 1993, 1995; Cassany, 1990, 1999; Castelló, 1995; García, 2000; 
García et al., 2001, 2002; Hayes, 1996; Olson, 1999) den prioridad a dos aspectos relacionados:

- La producción de textos en contextos comunicativos.

- El fomento de la actividad metacognitva durante la producción textual.

La legislación educativa vigente a través de las enseñanzas mínimas y del currículo está a favor de una enseñanza de la composición escrita que sea funcional para el alumno. Para ello apela a la necesidad de asimilar y conocer las convenciones de uso, estructura y forma para lograr una comunicación escrita y una representación de la realidad más eficaz. Enseñar a escribir será enseñar una gran diversidad de géneros discursivos específicos, cada uno de ellos con funciones propias y con unas características lingüísticas específicas.

Del análisis de la legislación se desprende que no se debe focalizar la enseñanzaaprendizaje de la composición escrita en un sólo enfoque, sino que es necesario la reorganización de la misma en torno a los enfoques basados en la función y en los procesos, potenciando los contenidos y no descuidando la gramática.

Del análisis de la estructura de los libros, de sus objetivos, contenidos, actividades, metodología y evaluación se desprende que:

- El enfoque predominante para la enseñanza de la composición escrita está basado tanto en la función como en los procesos que la hacen posible, tal y como lo recomienda la ley a través de los reales decretos 1006/1991 (BOE 152, 14 de junio de 1991) y 1344/1991 (BOE 220, 6 de septiembre de 1991) donde se establecen las enseñanzas mínimas y el currículo para el Área de Lengua Castellana y Literatura.

- Que, según lo expuesto en el punto anterior, aprender a escribir supone aprender a usar la lengua de forma adecuada a la situación y al contexto, como consecuencia será imprescindible aprender una gran variedad de géneros discursivos específicos, cada uno de ellos con sus funciones y características lingüísticas propias.

- No ajenos a los modelos actuales más relevantes sobre composición escrita así como la investigación amparada en el seno de la psicología cognitiva que avala 
dichos modelos $\mathrm{y}$ que ha puesto al descubierto los conocimientos metacognitivos sobre las personas, las tareas y las estrategias que el escritor pone en marcha antes, durante y después de una producción textual, se ha puesto especial énfasis en una serie de estrategias que permiten al alumno ser un escritor cada vez más experto y reflexivo y en situaciones de enseñanza y aprendizaje que permiten incidir en dicho proceso de construcción del discurso escrito.

- Se le da mucha importancia a la actividad del alumno mientras escribe en el intento de resolver el problema y por eso se incide para que: 1) conozca las estrategias más eficaces así como su uso apropiado; 2.) identifique y defina los problemas; 3.) planifique y secuencie las acciones necesarias para resolverlos y 4) supervise, compruebe, revise y evalúe la marcha sus planes (Mateos, 2001).

- La intervención educativa se ha centrado, por un lado, en ofrecer textos modelos a partir de los cuales se llevan a cabo diferentes operaciones de análisis y síntesis con el fin de internalizar estructuras textuales y de adquirir conocimientos. Por otro, se ofrecen ayudas para la mejora de los textos antes de que éstos estén finalizados (en forma de pautas, diálogos, revisiones grupales, etc.) y, por último, se muestra a los alumnos que escribir es un proceso complejo de reflexión, de construcción y reconstrucción textual, lo cual les permite modelizar la conducta para que conciban que escribir supone planificar, textualizar o redactar y revisar o reescribir.

Como síntesis de la revisión de los modelos teóricos, de la legislación educativa vigente y del tratamiento que recibe la composición escrita en los libros de textos para la educación primaria, podemos destacar una idea ampliamente compartida en la actualidad: la escritura es tanto producto como proceso. Se destaca la doble función que cumple el lenguaje escrito: comunicativa-interpersonal y representacional:

- Desde una perspectiva social es producto de la cultura y sus diferentes formas y usos deben ser interiorizados y enseñados para que sirvan como medio de comunicación y nos permitan interactuar con otras personas a través de la producción de textos. El lenguaje escrito es social por su origen en la interacción oral (Vygotsky, 1977) y por su naturaleza dialógica 
(Bakhtín, 1982). El contexto sociocultural compartido es el que permite la interacción y hace posible la comunicación.

- Desde una perspectiva individual, escribir es un proceso en tanto que es un instrumento privilegiado a través del cual se nos está permitido pensar y comunicar. Para Vygotsky, para el individuo que ha hecho suya la lengua escrita, cambian profundamente los modos de funcionamiento de percepción, de memoria y de pensamiento.

Por último, a pesar de que los modelos teóricos como los que acabamos de citar nos permitan ampliar el panorama sobre los procesos de aprendizaje de la escritura, y a pesar de que la legislación educativa vigente así lo recomiende, es indiscutible que, el papel del maestro y la motivación del alumno (en forma de intereses, expectativas y creencias) son dos aspectos que no se han comentado en este artículo y que pueden facilitar u obstaculizar dichos procesos. Permitir que el otro construya autónomamente no significa dejar al alumno a su suerte, significa acompañarlo como un escritor experto, que lee, que escucha, que revisa, que opina y que recomienda. En este sentido, el maestro se convierte en un colaborador que facilita la confrontación y el aprendizaje reflexivo.

\section{Referencias}

Allal, L. (1993). Regulations métacognitives: quelle place pour l'élève dans l'évaluation formative? En L. Allal, D. Bain, Ph. Perrenoud (1993) Évaluation formative et didactique dufrançais (pp. 81-98).Neûchatel, Delachaux et Niestlé

Bakhtín, M. M. (1982). El problema de los géneros discursivos. En M. M. Bakhtín La Estética de la Creación verbal (pp. 248-299). México: Siglo XXI.

Bereiter, C. y Scardamalia, M. (1987). The Psychology of Written Composition. Hillsdale, NJ: Erlbaum.

Bereiter, C. y Scardamalia, M. (1993). Enfoques de primero, segundo y tercer orden para mejorar las estrategias cognitivas de aprendizaje de la escritura. En J. Beltrán, V. Bermejo, M. D. Prieto y D. Vence (Eds.), Intervención Psicopedagógica, (pp. 51-63). Madrid: Pirámide. 
Bereiter, C., Burtis, P. J. y Scardamalia, M. (1988). Cognitive operations in constructing main points in written composition. Journal of Memory and Language, 27 (3), 261-278.

Bruer, J. T. (1997). Principiantes inteligentes: saber cómo aprender. En Escuelas para pensar. Una ciencia de aprendizaje en el aula, México, SEP (Biblioteca del normalista), pp. 75-90.

Camps, A. (1993). La enseñanza de la composición escrita: Una visión general. Cuadernos de Pedagogía, 216, 19-21.

Camps, A. (1995). Hacia un modelo de la enseñanza de la composición escrita en la escuela. Textos, 5, 21-28.

Cassany, D. (1990). Enfoques didácticos para la enseñanza de la expresión escrita. Comunicación, Lenguaje y Educación, 6, 63-80.

Cassany, D. (1999). Construir la Escritura. Barcelona: Paidós.

Castelló, M. (1995). Estrategias para escribir pensando. Cuadernos de pedagogía, 237, 23-28.

Cooper, Ch. R. y Matsuhashi, A. (1983). A Theory of the writing procesess. En M. Martlew (Ed.), The Psychology of Written Language, (pp. 3-40). New York: Wiley y Sons.

De Beaugrande, R. (1984). Text Production: Toward a sciencie of composition. Norwood: NJ, Ablex.

Flower, L. S. (1981). Problem-Solving Strategies for Writing. New York: Harcourt Brace Jovanovich.

Flower, L. S. y Hayes, J. R. (1980). The cognition of discovery: Defining a rhetorical problem. College Composition and Communication, 31 (1), 21-32.

García, S. J. N. (2000). El marco teórico de la escritura como construcción de significado. En J. N. García (coord.), De la psicología de la instrucción a las necesidades curriculares (pp. 241-260). Barcelona: Oikos-Tau.

García, S. J. N. y Marbán, J. (2001). Instrumento de evaluación individual de los procesos cognitivos de la escritura (IEPCE). En J. N. García Dificultades de aprendizaje e intervención psicopedagógica (pp. 141-149). Barcelona: Ariel.

García, S. J. N. y de Caso, A. (2002). ¿Es posible mejorar la productividad y coherencia de los textos escritos por alumnos con dificultades de aprendizaje y/o bajo rendimiento 
sin que cambie la disposición reflexiva de éstos hacia la escritura?, Psicothema, 14 (2), 456-462.

Guía de Servicios Educativos de Extremadura (2003-2004). Junta de Extremadura. Consejería de Educacuón, Ciencia y Tecnología.

Hayes, J. R. (1996). A New framework for understaing cognition and affect in writing. En M. Levy y S. Ransdell, The Science of Writing, (pp. 1-27), New Jersey: Lawrence Erlbaum Associates.

Hayes, J. y Flower, L. (1980). Identifying the organization of writing processes. En L. Gregg y E. Teinberg (Eds.). Cognitive Processes in Writing. (pp. 3-30). Hillsdale/Nueva York: Erlbaum.

Hull, D.L. (1996) A revolutionary philosopher of science. Nature, 382, 203-204.

Luria, A. R. (1980). Lenguaje y pensamiento. Barcelona: Fontanella.

Martlew, M. (1983). The Psychology of Written Lenguage. New York: Wiley y Ssons.

Mateos, M. (2001). Metacognición y Educación. Buenos Aires: Aiqué.

Miras, M. (2000). La escritura reflexiva. Aprender a escribir y aprender acerca de lo que se escribe. Infancia y Aprendizaje, 89, 65-80.

Olson, D. (1999). El mundo sobre el papel. El impacto de la escritura y la lectura en la estructura del conocimiento. Barcelona: Gedisa.

Real Decreto 1006/1991 de 14 de junio, publicado en el B.O.E. núm 152, miércoles 26 de junio de 1991.

Real Decreto 1344/1991 de 6 de septiembre, publicado en el B.O.E. núm 220, viernes 13 de septiembre de 1991.

Rivière, A. (1984). La Psicología de Vygotsky. Madrid: Visor.

Scardamalia, M. y Bereiter, C. (1985). Development of dialectical processes in composition. En D. Olson, N. Torrance y Hildyard (Eds.), Literacy, Language and Learning: The Nature and Consequences or Reading and Writing. Cambridge: Cambridge University Press.

Steinberg, E. R. (1980). A garden of opportunities and thicket of dangers. En L. W. Gregg y E. R. Steinberg (Eds.), Cognitive Processes in Writing (pp. 155-167). Hillsdale, NJ: Erlbaum. 
Vygotsky, L.S. (1977). Pensamiento y Lenguaje. Buenos Aires: La Pléyade.

Vygotsky, L.S. (1982-84). Sobraine socineii [Obras completas], Vols. I-VI. Moscú: Psagogika.

Vygotsky, L.S. (1985). Pensée et langage. París, Ed. Sociales.

Vygotsky, L.S. (1987). Thinking and speech. Nueva York: Plenum Press. 